\title{
Quantitative magnetic resonance imaging as marker of synovial membrane regeneration and recurrence of synovitis after arthroscopic knee joint synovectomy: a one year follow up study
}

\author{
M Østergaard, B Ejbjerg, M Stoltenberg, P Gideon, B Volck, K Skov, C Hjorth Jensen,
} I Lorenzen

\begin{abstract}
Objectives-By repeated magnetic resonance imaging (MRI) to study synovial membrane regeneration and recurrence of synovitis after arthroscopic knee joint synovectomy in patients with rheumatoid arthritis (RA) and other (non-RA) causes of persistent knee joint synovitis.

Methods-Contrast enhanced MRI was performed in 15 knees (nine RA, six non-RA) before and one day, seven days, two months, and 12 months after arthroscopic synovectomy. Synovial membrane volumes, joint effusion volumes, and cartilage and bone destruction were assessed on each MRI set. Baseline microscopic and macroscopic assessments of synovitis and baseline and follow up standard clinical and biochemical examinations were available.

Results-Synovial membrane and joint fluid volumes were significantly reduced two and 12 months after synovectomy. However, MRI signs of recurrent synovitis were already present in most knees at two months. No significant differences between volumes in RA and non-RA knees were seen. Synovial membrane volumes at two months were significantly inversely correlated with the duration of clinical remission, for all knees considered together (Spearman's correlation $\left.r_{\mathrm{s}}=-0.67 ; \mathrm{p}<0.05\right)$, for RA knees $\left(r_{\mathrm{s}}=-0.76\right.$; $\mathrm{p}<0.05)$, and for non-RA knees $\left(r_{\mathrm{s}}=-0.83\right.$; $\mathbf{p}<0.05)$. Baseline volumes were not significantly correlated with clinical outcome. Only three knees (all RA) showed erosive progression. The rate of erosive
\end{abstract}

progression was not correlated with MRI volumes or with clinical or biochemical parameters.

Conclusion-The synovial membrane had regenerated two months after arthroscopic knee joint synovectomy and despite significant volume reductions compared with baseline it often showed signs of recurrent synovitis. MRI seems to be valuable as a marker of inflammation, destruction and, perhaps, as a predictor of therapeutic outcome in arthritis.

(Ann Rheum Dis 2001;60:233-236)

Arthroscopic synovectomy is an accepted therapeutic option in knee joint synovitis resistant to treatment. Clinical efficacy data vary, but are generally encouraging, with clinical remission or marked improvement in most patients after two years. ${ }^{1-7}$

However, longitudinal studies, which with sensitive methods follow the regeneration of the synovium and analyse the timing and frequency of recurrent synovial inflammation and its relation to progressive bone destruction, are lacking, probably mainly owing to the lack of non-invasive follow up methods.

Magnetic resonance imaging (MRI) allows reliable estimation of volumes of inflamed synovial membrane in arthritic knee joints. ${ }^{8-11}$ Furthermore, MRI visualises destructive bone changes better than conventional radiography. ${ }^{12-15}$

The aim of the present investigation was, by performing repeated MRI, to study synovial regeneration and the recurrence of synovitis after arthroscopic knee joint synovectomy in

Rigshospitalet,

University of

Copenhagen, Denmark

$M \emptyset$ Øtergaard

B Ejbjerg

M Stoltenberg

P Gideon

B Volck

K Skov

C Hjorth Jensen

I Lorenzen

Correspondence to: Dr M Østergaard, Danish Research Centre of Magnetic Resonance, Hvidovre University Hospital, DK-2650 Hvidovre, Denmark

mo@dadlnet.dk

Table 1 Baseline data. Values are medians (ranges in parentheses). NS indicates no significant difference

\begin{tabular}{|c|c|c|c|c|}
\hline & All knees & $R A$ knees & Non-RA knees & $\begin{array}{l}\text { Mann-Whitney } \\
(R A \text { v non-RA) }\end{array}$ \\
\hline Number of knees (patients) & $15(12)$ & $9(7)$ & $6(5)$ & \\
\hline Age (years) & $58(20-70)$ & $64(20-70)$ & $25(20-60)$ & $\mathrm{p}<0.01$ \\
\hline Duration of knee symptoms (years) & $2(0.2-13)$ & $2(0.2-13)$ & $2.5(0.2-10)$ & $\mathrm{p}<0.05$ \\
\hline Knee pain $\left(\right.$ VAS $\left.^{\star}\right)$ & $6.3(2.8-10)$ & $7.2(5.7-10)$ & $3.7(2.8-8.8)$ & NS \\
\hline Number of swollen and/or tender joints & $5(1-26)$ & $7(5-26)$ & $1.5(1-5)$ & $\mathrm{p}<0.01$ \\
\hline Serum $\mathrm{CRP}^{\star}(\mathrm{nmol} / \mathrm{l})$ & $170(30-1590)$ & $324(50-1413)$ & $119(30-1590)$ & NS \\
\hline $\mathrm{ESR}^{\star}(\mathrm{mm} / 1 \mathrm{st} \mathrm{h})$ & $42(8-95)$ & $45(10-95)$ & $41(8-70)$ & NS \\
\hline Macroscopic synovitis (average grade) & $3.3(1.0-4.0)$ & $3.3(1.0-3.8)$ & $3.1(2.3-4.0)$ & NS \\
\hline Histological synovitis (average grade) & $1.8(0.3-2.7)$ & $1.8(1.2-2.7)$ & $1.9(0.3-2.0)$ & NS \\
\hline Synovial membrane volume $\left(\mathrm{cm}^{3}\right)$ & $62(21-177)$ & $59(46-128)$ & $66(21-177)$ & NS \\
\hline Joint fluid volume $\left(\mathrm{cm}^{3}\right)$ & $45(6-173)$ & $36(15-94)$ & $70(6-173)$ & NS \\
\hline Bone erosion score & $0(0-5)$ & $1(0-5)$ & $0(0-1)$ & $\mathrm{p}<0.05$ \\
\hline Progression in bone erosion score & $0(0-4)$ & $0(0-4)$ & $0(0)$ & NS \\
\hline Duration of clinical remission (days) & $360(60-360)$ & $330(60-360)$ & $360(60-360)$ & NS \\
\hline
\end{tabular}

*VAS = visual analogue scale; $\mathrm{CRP}=\mathrm{C}$ reactive protein; $\mathrm{ESR}=$ erythrocyte sedimentation rate. 

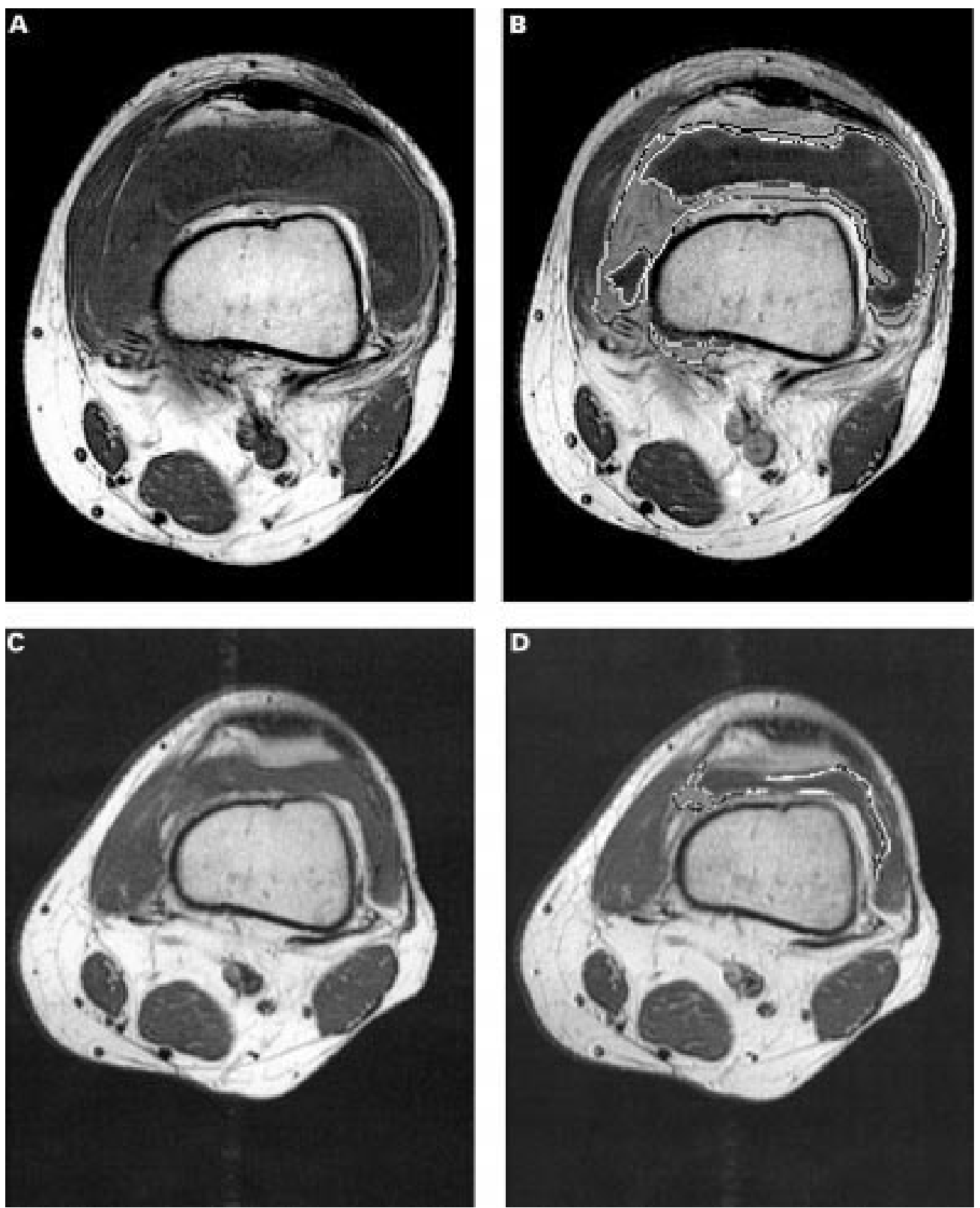

Figure 1 Transversal $T_{1}$ weighted spin echo magnetic resonance images through the suprapatellar recess. $(A, B) B e f o r e$ arthroscopic synovectomy, $(A)$ before and $(B)$ after intravenous injection of $G d-D T P A$. After intravenous $G d-D T P A$ the signal intensity of the synovial membrane (outlined) has increased markedly, while the joint fluid remains dark grey. MRI determined synovial membrane and joint fluid volumes were $177 \mathrm{~cm}^{3}$ and $173 \mathrm{~cm}^{3}$, respectively. (C, D) Corresponding images two months after arthroscopic synovectomy, showing regeneration of the synovial membrane and, despite markedly decreased signs of joint inflammation, some synovitis and joint effusion (volumes $45 \mathrm{~cm}^{3}$ and $12 \mathrm{~cm}^{3}$, respectively).

patients with rheumatoid arthritis (RA) and other (non-RA) causes of persistent knee joint synovitis. Furthermore, we attempted to assess whether MRI signs of synovitis were related to subsequent erosive progression or clinical outcome, or both.

\section{Material and methods}

PATIENTS

Fifteen knees of 12 patients scheduled for arthroscopic synovectomy were included. The underlying disease was RA (American College of Rheumatology 1987 criteria $^{16}$ ) in nine knees (seven patients), while six knees (five patients) had other (non-RA) causes of persistent arthritis (juvenile RA: two knees (one patient), unspecified monarthritis: three knees; osteoarthritis: one knee). Table 1 shows baseline patient characteristics.

CLINICAL PROCEDURE

MRI, standard blood tests (including serum C reactive protein (CRP) and erythrocyte sedimentation rate (ESR)), and a clinical examination (including assessment of swelling and tenderness of the treated joint and swollen and tender joint counts) were obtained before surgery, and one day, seven days, two months, and 12 months after surgery. Clinical relapse was diagnosed, if clinical knee joint swelling recurred. 
Table 2 Synovial membrane and joint fluid volumes after arthroscopic synovectomy. Values are medians (ranges in parentheses). NS indicates no significant difference

\begin{tabular}{|c|c|c|c|c|}
\hline & All knees & RA knees & Non-RA knees & $\begin{array}{l}\text { Mann-Whitney } \\
(R A \text { v non-RA) }\end{array}$ \\
\hline \multicolumn{5}{|c|}{ Synovial membrane volumes $\left(\mathrm{cm}^{3}\right)$} \\
\hline Month 0 & $62(21-177)$ & $59(46-128)$ & $66(21-177)$ & NS \\
\hline Month 2 & $49(18-86)$ & $49(19-86)$ & $50(18-74)$ & NS \\
\hline Month 12 & $44(1-73)$ & $42(9-73)$ & $45(1-61)$ & NS \\
\hline \multicolumn{5}{|c|}{ Wilcoxon-Pratt test ( $\mathrm{p}$ value) } \\
\hline Month $0 v 2$ & $<0.05$ & NS (0.09) & $<0.05$ & \\
\hline Month $0 v 12$ & $<0.01$ & $<0.05$ & NS (0.06) & \\
\hline Month $2 v 12$ & NS $(0.16)$ & NS $(0.74)$ & NS $(0.08)$ & \\
\hline \multicolumn{5}{|c|}{ Joint fluid volumes $\left(\mathrm{cm}^{3}\right)$} \\
\hline Month 0 & $45(6-173)$ & $36(15-94)$ & $70(6-173)$ & NS \\
\hline Month 2 & $18(3-49)$ & $28(6-40)$ & $11(3-49)$ & NS \\
\hline Month 12 & $17(0-77)$ & $18(5-77)$ & $15(0-47)$ & NS \\
\hline \multicolumn{5}{|c|}{ Wilcoxon-Pratt test ( $\mathrm{p}$ value) } \\
\hline Month 0 v 2 & $<0.01$ & $<0.05$ & $<0.05$ & \\
\hline Month $0 v 12$ & $<0.05$ & NS $(0.31)$ & $<0.05$ & \\
\hline Month $2 v 12$ & NS (0.66) & NS $(0.80)$ & NS $(0.50)$ & \\
\hline
\end{tabular}

SURGICAL PROCEDURE

Firstly, at four preselected sites, macroscopic signs of synovitis were graded (grade 0-3: none, mild, moderate, severe) and synovial biopsy specimens were obtained. The synovial membrane biopsy specimens were graded similarly by a histopathologist for histological signs of synovitis. Details of the methods for macroscopic and histological grading of synovitis are described by Østergaard et al. ${ }^{11}$ Secondly, as much synovium as possible was removed by a synovial resector, equipped with a suction device, through three to four portals (anteromedially, anterolaterally, and one to two portals in the suprapatellar recess).

MRI

Continuous transversal and sagittal $T_{1}$ weighted spin echo MR images (TR/TE/slice thickness $=500-750 \mathrm{~ms} / 15-17 \mathrm{~ms} / 5 \mathrm{~mm}$ ) were obtained on a 1.5 Tesla Siemens (Erlangen, Germany) Magnetom before and after intravenous injection of $0.05 \mathrm{mmol}$ gadoliniumDTPA (Schering, Berlin, Germany)/kg body weight (fig 1).

MRI ASSESSMENT OF SYNOVIAL MEMBRANE AND JOINT FLUID VOLUMES

By means of image processing software, the synovial membrane and the joint fluid of each transverse MRI slice were outlined and the areas automatically calculated. Total volumes of synovial membrane and joint fluid were calculated by summation of slices. Methodological details have been described by $\emptyset$ stergaard et al..$^{11}$

MRI ASSESSMENT OF CARTILAGE AND BONE

EROSIONS

Each of six regions was graded as follows: $0=$ no erosions; 1 = non-penetrating pannusinduced cartilage erosions; $2=$ penetrating pannus-induced cartilage erosions; $3=$ presence of bone erosions. An erosion score, calculated as the sum of the gradings, was calculated. Methodological details have been described by $\varnothing$ stergaard et al. ${ }^{15} 17$

STATISTICAL METHODS

Non-parametric methods were used for statistical analysis. The Mann-Whitney test (two sample rank sum test) was used to analyse dif- ferences between groups of patients and the Wilcoxon-Pratt test (one sample signed rank sum test) to analyse changes within the patient. Analysis of statistical correlation was performed by the Spearman test of rank correlation.

\section{Results}

Table 1 shows baseline data. MR images obtained at one and seven days after surgery were characterised by massive amounts of intra-articular debris, effusion, and bleeding, and diffuse enhancement from the periphery of the joint cavity was seen. As a consequence, only results from baseline and months 2 and 12 are reported.

At baseline, median synovial membrane volumes were $59 \mathrm{~cm}^{3}$ (range 46-128) in RA knees and $66 \mathrm{~cm}^{3}$ (range 21-177) in non-RA knees. Volumes of membrane and fluid were significantly reduced after two months and 12 months, compared with baseline (table 2). However, considerable amounts of synovium (two months: median $49 \mathrm{~cm}^{3}$ (range 18-86)) and effusion (two months: median $18 \mathrm{~cm}^{3}$ (range 3-49)) were still present. No significant differences between volumes in RA and non-RA knees were seen at any time.

Synovial membrane volumes at month 2 were significantly inversely correlated with the duration of clinical remission for all knees considered together $\left(r_{\mathrm{s}}=-0.67 ; \mathrm{p}<0.05\right), \mathrm{RA}$ knees $\left(r_{\mathrm{s}}=-0.76 ; \mathrm{p}<0.05\right)$, and non-RA knees $\left(r_{\mathrm{s}}=-0.83 ; \mathrm{p}<0.05\right)$. Baseline volumes were not significantly correlated with clinical outcome.

Only three knees (two patients, both with RA) showed erosive progression. The rate of erosive progression was not statistically correlated with synovial membrane or effusion volumes or with clinical or biochemical parameters.

\section{Discussion}

This study introduces follow up of synovial regeneration, recurrence of synovitis, and erosive progression after arthroscopic synovectomy in arthritic knees by means of the best currently available non-invasive technique, MRI.

Volumes of synovium and joint fluid decreased after arthroscopic synovectomy, in accordance with a study by Fiocco et $a l,{ }^{18}$ which reported reduced synovial membrane thickness and joint effusion two months after knee joint arthroscopic synovectomy, when assessed by ultrasonography. On the other hand, a considerable amount of inflamed synovium was found in many knees at both two and 12 months after synovectomy (table 2), indicating that the synovium quickly regenerates and that recurrence of some degree of synovitis after a few months is common.

Images from days 1 and 7 could not be properly interpreted owing to post-surgical changes. Thus no imaging evidence of the completeness of synovectomies was available. However, at least in the most accessible areas such as the suprapatellar and parapatellar recesses, there is no doubt that all the synovium was removed. Also, in these areas, synovitis was 
commonly found at two months, verifying the occurrence of regeneration of synovium and recurrence of synovitis.

An inverse correlation between synovial membrane volumes at month 2 and the duration of clinical remission was found, suggesting a prognostic value of MRI for treatment outcome. A previous study showed a correlation between pretreatment synovial membrane volumes determined by MRI and the duration of clinical remission in RA knees treated with intra-articular corticosteroid. ${ }^{17} \mathrm{~A}$ relation between pretreatment MRI signs of synovitis and the rate of subsequent erosive progression during treatment with disease modifying antirheumatic drugs, non-steroidal antirheumatic drugs, and/or prednisolone has been described in the wrists of patients with established $^{19}$ and early ${ }^{20}$ RA. No correlation between pretreatment MRI signs of synovitis and erosive progression was found in the present study. The character of the treatment (surgery), the small number of patients, and the few new erosions are probable main causes.

In summary, the synovial membrane had regenerated two months after arthroscopic knee joint synovectomy and it often showed signs of recurrent synovitis. However, compared with pretreatment values, synovial membrane and joint fluid volumes were significantly reduced both two and 12 months after synovectomy. Synovial membrane volumes two months after arthroscopic synovectomy were inversely correlated with the duration of clinical remission. In addition to sensitive assessment of joint inflammation and destruction, MRI may have a value as predictor of long term therapeutical effect in arthritis.

The authors thank nurse Brigitta Pedersen-Zbinden for clinica management of the patients and Jens Arnth Jensen and Poul management of the patients and Jens Arnth Jensen and Poul Ring for development of image processing software. We acknowledge the Foundation of 17-12-81, the University of Copenhagen, the Thomas and Elisabeth Frolund Nielsen Foundation, the Danish Rheumatism Association, the Danish Medical Research Council, Johann and Hanne Weimann born Seedorf's grant, Karen Marie Jørgensen and Datters grant and the Danish Hospital Foundation for Medical Research, Region of Copenhagen, the Faroe Islands, and Greenland for financia support. Schering Diagnostika, Denmark, is acknowledged for providing the contrast agent.

1 Arnold W, Kalunian K. Arthroscopic synovectomy by rheumatologists: time for a new look. Arthritis Rheum 1989;32:108-11

2 Pages M, Poey C, Lassoued S, Fournie B, Railhac JJ. MR imaging of the knee in rheumatoid arthritis and other rheumatic diseases. Am J Roentgenol 1991;157:1128.
3 Fiocco U, Cozzi L, Rigon C, Chieco-Bianchi F, Baldovin M, Cassisi GA, et al. Arthroscopic synovectomy in rheumatoid and psoriatic knee joint synovitis: long-term outcome. $\mathrm{Br} \mathrm{J}$ Rheumatol 1996;35:463-70.

4 Smiley P, Wasilewski S. Arthroscopic synovectomy. Arthroscopy $1990 ; 6: 18-23$.

5 Matsui $\mathrm{N}$, Taneda $\mathrm{Y}$, Ohta $\mathrm{H}$, Itoh $\mathrm{T}$, Tsuboguchi S. Arthroscopic versus open synovectomy in the rheumatoid knee. Int Orthop 1989;13:17-20.

6 Combe B, Krause E, Sany J. Treatment of chronic knee synovitis with arthroscopic synovectomy after failure of intraarticular injection of radionucleide. Arthritis Rheum 1989;32:10-14

7 Ogilvie-Harris DJ, Basinski A. Arthroscopic synovectomy of the knee for rheumatoid arthritis. Arthroscopy 1991;7: 91-7.

8 Waterton JC, Rajanayagam V, Ross BD, Brown D, Whittemore A, Johnstone D. Magnetic resonance methods for measurement of disease progression in rheumatoid arthritis. Magn Reson Imaging 1993;11:1033-8.

9 Østergaard M, Gideon P, Henriksen O, Lorenzen I. Synovial volume - a marker of disease severity in rheumatoid arthritis? Quantification by MRI. Scand J Rheumatol 1994;23: 197-202.

10 Østergaard M, Stoltenberg M, Henriksen O, Lorenzen I. The accuracy of MRI-determined synovial membrane and joint effusion volumes in arthritis. A comparison of preand post-aspiration volumes. Scand J Rheumatol 1995;24: 305-11

11 Østergaard M, Stoltenberg M, Løvgreen-Nielsen P, Volck B, Jensen $\mathrm{CH}$, Lorenzen I. Magnetic resonance imagingdetermined synovial membrane and joint effusion volumes in rheumatoid arthritis and osteoarthritis. Comparison with the macroscopic and microscopic appearance of the synovium. Arthritis Rheum 1997;40:1856-67.

12 Yulish BS, Lieberman JM, Newman AJ, Bryan PJ, Mulopulos GP, Modic MT. Juvenile rheumatoid arthritis: assessment with MR imaging. Radiology 1987;165:149-52

13 Poleksic L, Zdravkovic D, Jablanovic D, Watt I, Bacic G. Magnetic resonance imaging of bone destruction in rheumatoid arthritis: comparison with radiography. Skeletal Radiol 1993;22:577-80.

14 Hervé-Somma CMP, Sebag GH, Prieur A, Bonnerot V, Lallemand DP. Juvenile rheumatoid arthritis of the knee: MR evaluation with Gd-DOTA. Radiology 1992;182:93-8.

15 Østergaard M, Gideon P, Wieslander S, Henriksen O, Lorenzen I. Pannus-induced destruction of joint cartilage and subchondral bone. Visualization and staging by MRI. MAGMA 1994;2:91-100.

16 Arnett FC, Edworthy SM, Bloch DA, McShane DJ, Fries JF, Cooper NS, et al. The American Rheumatism Association 1987 revised criteria for the classification of rheumatoid arthritis. Arthritis Rheum 1988;31:315-24.

17 Østergaard M, Stoltenberg M, Gideon P, Sørensen K, Henriksen O, Lorenzen I. Changes in synovial membrane and joint effusion volumes following intraarticular methylprednisolone. Quantitative assessment of inflammatory and destructive changes in rheumatoid arthritis by MRI. J Rheumatol 1996;23:1151-61.

18 Fiocco U, Cozzi L, Rubaltelli L, Rigon C, de Candia A, Tregnaghi A, et al. Long-term sonographic follow-up of heumatoid and psoriatic proliferative knee joint synovitis. Br J Rheumatol 1996;35:155-63.

19 Østergaard M, Hansen M, Stoltenberg M, Gideon P, Klarlund $\mathrm{M}$, Jensen $\mathrm{KE}$, et al. Magnetic resonance imagingdetermined synovial membrane volume as a marker of disease activity and a predictor of progressive joint destruction in the wrists of patients with rheumatoid arthritis. Arthritis in the wrists of patients with

20 McQueen FM, Stewart N, Crabbe J, Robinson E, Yeoman $\mathrm{S}$, Tan PLJ, et al. Magnetic resonance imaging of the wrist in early rheumatoid arthritis reveals progression of erosions despite clinical improvement. Ann Rheum Dis 1999;58: $156-63$. 